University of New Hampshire

University of New Hampshire Scholars' Repository

Applied Engineering and Sciences Scholarship

Applied Engineering and Sciences

$1-1-2018$

\title{
An Overview of the New ACM/IEEE Information Technology Curricular Framework
}

Hala Alrumaih

Al Imam Mohammad Ibn Saud Islamic University

Mihaela C. Sabin

University of New Hampshire, Manchester, mihaela.sabin@unh.edu

John Impagliazzo

Hofstra University

Follow this and additional works at: https://scholars.unh.edu/unhmcis_facpub

Comments

This is an Author's Manuscript of an article published by IEEE in 2018 IEEE World Engineering Education Conference in 2018, available online: https://ieeexplore.ieee.org

\section{Recommended Citation}

Alrumaih, Hala, Mihaela Sabin, and John Impagliazzo. 2018. "An Overview of the New ACM/IEEE Information Technology Curricular Framework." In 2018 IEEE World Engineering Education Conference. Buenos Aires, Argentina: IEEE Xplore.

This Conference Proceeding is brought to you for free and open access by the Applied Engineering and Sciences at University of New Hampshire Scholars' Repository. It has been accepted for inclusion in Applied Engineering and Sciences Scholarship by an authorized administrator of University of New Hampshire Scholars' Repository. For more information, please contact Scholarly.Communication@unh.edu. 


\section{An Overview of the New ACM/IEEE Information Technology Curricular Framework}

\author{
Hala Alrumaih \\ Al Imam Mohammad Ibn Saud \\ Islamic University \\ Riyadh, Saudi Arabia \\ haalrumaih@imamu.edu.sa
}

\author{
Mihaela Sabin \\ University of New Hampshire \\ Manchester, United States \\ mihaela.sabin@unh.ede
}

\author{
John Impagliazzo \\ Hofstra University \\ New York, United States \\ john.impagliazzo@hofstra.edu
}

\begin{abstract}
ACM and IEEE have developed a curricular report titled, "Information Technology Curricula 2017: Curriculum Guidelines for Baccalaureate Degree Programs in Information Technology," known also as IT2017. The development of this report has received worldwide content contributions from industry and academia through surveys as well as many international conferences and workshops. An open online publication of the report was made available in December 2017. This paper presents a digest of the content of the report, the IT curricular framework, and suggestions for its use in developing new information technology programs or enhancing existing ones. The heart of the IT curricular framework is a set of competencies identified through knowledge, skills, and dispositions, as supported by pedagogical research. The paper also describes ways in which institutions could use the curricular framework not only to develop information technology degree programs, but also to improve and enhance related computing programs.
\end{abstract}

Keywords-Information technology; IT education; IT competencies; IT curricular framework; IT curriculum guidelines

\section{INTRODUCTION}

The Association for Computing Machinery (ACM) and the IEEE Computer Society (IEEE-CS) produced many curricular documents for computing and engineering studies at the baccalaureate level. One of the documents that they developed recently is a report titled, "Information Technology Curricula 2017: Guidelines for Baccalaureate Degree Programs in Information Technology [1], published in December of 2017. This conference paper provides an overview of the report and the IT curricular framework. The paper also describes ways in which institutions could use the curricular framework to develop information technology degree programs, and to improve and enhance related computing programs.

Over the years, the Association for Computing Machinery (ACM) has spearheaded many efforts to produce a series of curricular documents [2] that are ongoing even today. In 2008, ACM and the IEEE Computer Society (IEEE-CS) issued the first curricular report for information technology (IT), called IT2008 [3]. Many new technologies developed and flourished since that time. In 2012-2013, ACM formed a preliminary committee to decide if IT2008 required updating. After an affirmative response, ACM formed a task group for developing an update of IT2008 that was properly forward looking to successfully prepare graduates in the mid-2020s. The report, tagged IT2017, is the 2017 document "Information Technology Curricula 2017: Guidelines for Baccalaureate Degree Programs in Information Technology", known also as IT2017.

Developing such guidelines for rigorous, high quality IT degree programs benefits from an inclusive approach that engages international perspectives and reflects needs and expectations from IT professional societies and industry $[4,5$, 6]. The IT2017 report is the second edition of the ACM/IEEECS Curriculum Guidelines for Baccalaureate Programs in Information Technology; it encompasses technology and educational advances that occurred since 2008 [7]. The report replaced its predecessor, the IT2008 report, at the end of 2017.

\section{IT2017 TASK GROUP}

The IT2017 task group is the committee who developed these guidelines. Its membership consists of twelve professionals, five of whom form the task group's executive committee. These twelve professionals represent academia (nine) and industry (three). The task group membership encompasses three continents (Asia, Europe, North America) and five countries (Canada, China, Netherlands, Saudi Arabia, United States). The group members represent many international societies, including ACM, IEEE-CS, two ACM special interest groups (IT Education and Computer-Human Interaction), and other organizations.

The IT2017 task group has worked carefully to make revisions and create a forward-looking document that is globally relevant and balances perspectives from IT professionals, practitioners, and educators. The novelty of the report is captured succinctly in the Executive Summary:

"The IT2017 task group holds the view that IT programs should prepare students with knowledge and skills in learning contexts that emphasize development of competencies: what students do and how they demonstrate performance with what they know. The main goal of this group is to produce a curricular framework and guidelines for worldwide baccalaureate IT degree programs that prepare graduates professionally for current and new technologies for the next decade. To accomplish this goal, the task group has incorporated the results of previous curricular reports as a backdrop for its activities. These include reports on computer engineering, computer science, information systems, and software engineering. In addition, the group decided to conduct many 
faculty and industry surveys to ascertain multinational indicators, predictors, and sources surrounding information technology as an academic discipline and industry sector." $[1, \mathrm{p} 9]$

\section{IT2017 REPORT}

\section{A. Vision and Mission}

The IT2017 task group has adopted both a vision and a mission for the project as described in Chapter 1:

"The IT2017 report will become a sought-after and durable set of guidelines for use by educational institutions around the world to help them develop IT curricula for the next ten years!" [1, p11]

"Knowledge alone is not sufficient to be productive in the changing information technology world. IT competencies require skills and dispositions that complement knowledge to achieve professional expectations of a modern workplace. Therefore, the mission of the IT2017 project is to produce a globally accepted document of information technology competencies appropriate for baccalaureate degree programs that meets the growing demands of the changing technological world and that is useful for both industry and academia." [1, p11]

\section{B. Public Comment}

The report includes feedback that the task group received from public comment and review solicited for report versions in January of 2015, August of 2016, and May of 2017. Some task group members participated in two international working groups $[5,6]$ to lead extensive data gathering and analysis efforts and to garner input from academia and industry through surveys conducted in 2015 (almost 700 responses, 597 computing faculty and 91 industry respondents) and in 2016 (over 350 responses from Latin America, 182 faculty and 177 employers). Report development dissemination included a variety of venues to engage educational and professional communities worldwide: birds-of-a-feather discussion group at SIGCSE'15 in Kansas City [8]; curriculum design workshop and panel at IEEE EDUCON in Tallinn, Estonia in 2015 [9] and Abu Dhabi in 2016 [10], and a panel in the $1^{\text {st }}$ National Computing Colleges Conference in Saudi Arabia [11] in 2016. Other panel sessions on the report status updates occurred at SIGITE conferences in Chicago in 2015, Boston in 2016 [12], and Rochester 2017 [13], at the Western Canadian Conference on Computing Education (WCCE'16) in British Columbia, Canada [14], and at ITiCSE'16 in Arequipa, Peru [15].

\section{Content of the IT2017 Report}

The IT2017 report has curriculum guidelines for baccalaureate degree programs in information technology. The primary body of the report consists of eight chapters. Chapter 1 introduces the report. Chapter 2 discusses the role of IT among other computing disciplines and proposes a new definition for the information technology discipline. It also describes competencies that students develop through their program of study and should demonstrate upon graduation. Chapter 3 focuses on the importance of professionalism in the practice of information technology. Chapter 4 considers the meaning of competencies and proposes an operational definition for information technology competencies.

Chapter 5 reviews an industry perspective toward information technology. It includes current data and graphs related to IT competencies from IT employers' viewpoint.
Chapter 6 gives an overview of the IT curricular framework and describes a basis for curricular recommendations. The vision, mission, goals, underlying principles, perspectives from industry, and professional practice inform this framework. The chapter also articulates various IT competency domains of the curricular framework, the percent of time devoted to an IT curriculum in a degree program, mathematics and science curricular requirements, and various competencies an individual need to become an effective professional in information technology.

Chapter 7 presents a discussion on transforming competencies into a curriculum; it also considers issues affecting the implementation of an IT curriculum such as the arrangement of a student's program of study, inclusion of courses within the major and those in other areas of the educational experience as well as other implementation considerations. Chapter 8 deliberates some challenges that may arise when creating or continuing IT programs such as curriculum design, computing resources, and faculty issues.

Most of the material in the report appears as five appendices. Appendix A offerings part of the first chapter in the Enterprise Information Technology Body of Knowledge (EITBOK) report currently under development by the IEEE Computer Society. Appendix B provides examples of IT performances related to various IT domains and their subdomains. These performances may be useful for developing learning outcomes for a given IT course or possible questions to assess student performance. Appendix C shows typical sample curricula that might appear at different academic institutions together with related mappings of the framework and course descriptions. Appendix D delivers samples of other IT programs (e.g., interdisciplinary, threeyear, 2+2, etc.). Appendix E recognizes reviewer contributors.

\section{IT2017 CURRICULAR FRAMEWORK}

The IT2017 report is intentional about a learner-centered framework for IT programs and successful preparation of graduates for professional careers or further academic study. Inspired by the IT competency model for an associate degree curriculum [16] and receptive to industry demands for competent and competitive IT workforce, the IT2017 report has applied a competency-based approach to learning IT to the development of its guidelines. We argue that such approach is somewhat unique among the ACM/IEEE curricular reports. The report formulates competencies based on content of essential and supplemental IT domains. It enables computing faculty to implement IT programs mindful of what student should be able to achieve when they graduate.

The IT2008 report's depiction of the IT discipline represented five distinct areas of study, metaphorically called "pillars", which were built on a "foundation" of IT fundamentals and were "overarched" by information assurance and security and professionalism. The "pillars" in the IT2007 model curriculum were programming, networking, human computer interaction, databases, and web systems. For the current situation, the IT2017 framework depiction is an interwoven tapestry in which studies and activities are closely interrelated. Another innovative change is the elimination of hours as a measure of domain coverage. A competent graduate 
from an IT degree program should experience the equivalent of at least 1.5 years of information technology studies. The report provides guidance so IT graduates can perform competitively in the marketplace. It is possible to consider that a report of this type is much too complex with framework domains and associated competencies.

"In today's computing educational environments, it is simply not possible to list only a set of courses with their lists of topics. IT programs vary among institutions. Furthermore, the technological field changes rapidly and what seems important today may just be a passing fancy. Thus, it is important to prepare students for this undetermined future by establishing foundational competencies coupled with the flexibility to adapt to new situations that await them after graduation.” [1, p13]

\section{A. Structure of the IT2017 Curricular Framework}

The organization of the IT domains collectively represents the scope of IT. It is critical to note that an IT domain does $\underline{\text { not }}$ mean a course.

"The IT domains decompose into subdomains, with an identifying numeric suffix to the domain identification; as an example, ITENET-2 is subdomain within the network domain. A set of competencies and a set of scope statements further describe IT domains. Some competencies relate to or are dependent upon other competencies. The report does not distinguish such dependencies. For example, problem solving strategies, testing and iterative refinement, and the use of data and procedural abstractions create a learning progression for programming practice." $[1, \mathrm{p} 46]$

1) Essential and Supplemental Domains: One of the goals in this IT2017 report is to preserve the implementation requirements of the IT curricular framework as few as possible to allow flexibility for programs in information technology.

"To implement this principle, a distinction among the IT domains occurs by identifying those that are essential to an IT curriculum compared to those that are supplemental. Essential domains encompass competencies that anyone obtaining an IT degree must acquire. Supplemental domains encompass competencies in domains where students do more specialized work according to the goals of a program." [1, p46]

The report continues by stating:

"Supplemental domains provide IT programs more directed choices, flexibility, and the opportunity to include new domains that could emarge in the future. All degree programs should require students to achieve competencies in some subset of the supplemental domains." [1, p46]

2) Building an IT Curriculum of an IT Degree Program: For the purpose of this paper, the entire curriculum of a complete IT degree program contains IT, mathematics, science, and other curricular requirements.

"The IT2017 task group recommends that the essential IT domains should be at least $15 \%$ of an IT degree. In addition, the task group recommends that the supplemental IT domains should be approximately $7.5 \%$ of an IT degree program. The remaining $15 \%$ of an IT degree program are IT elective courses that represent requirements reflecting the goals, mission, and resources of individual IT degree programs. IT electives are entirely decided and configured by IT faculty in response to student interests and local employers' needs." [1, p47]
Fig. 1, taken from [1, p47], illustrates the structure of an IT curriculum in a baccalaureate IT degree program of 120 credits.

3) IT Curriculum Breakout: Table I shows the IT domains as existing in the report together with their essential or supplemental categories. Note that some domains cross both essential and supplemental categories. The table also shows the percent related with each domain relative to the entire IT curriculum in an baccalaureate IT degree program.

"The IT2017 task group has recommended that the breakdown of IT curriculum in a degree program consists of approximately $40 \%$ from the essential IT domains, approximately $20 \%$ from the supplemental IT domains, and the remaining $40 \%$ representing IT electives. To accomplish $20 \%$ of the IT curriculum that comes from the supplemental IT domains, programs have various options. For example, a program could choose five 4\% supplemental domains. Another possibility is to take six supplemental domains with relative percents of $4 \%, 4 \%, 4 \%, 4 \%, 2 \%$, and $2 \%$. Each IT program should choose supplemental domains to reflect the goals and the mission of the program." [1, p48]

4) Tags for IT Domains: All IT domains, essential and supplemental, have identifying tags.

"These tags always contain the prefix "IT_" to distinguish them from other related computing curricula reports. The task group uses "ITE" for essential IT domains, "ITS" for supplemental IT domains, and "ITM" for mathematics domains in an IT degree program. Each IT domain has a three-letter abbreviation such as IOT for representing internet of things. As a result, each domain contains two parts separated by a hyphen. For example, the task group uses ITE-UXD to represent "user experience design" as an essential IT domain, and ITS-VSS for representing "virtual systems and services" as a supplemental IT domain. Subdomains of each IT domain contain numbers for identification purposes." $[1, \mathrm{p} 49]$

5) Level of Learning Engagement: The report uses a level system as an indicator of learning engagement to provide readers a sense of student learning of IT competencies in this curricular framework.

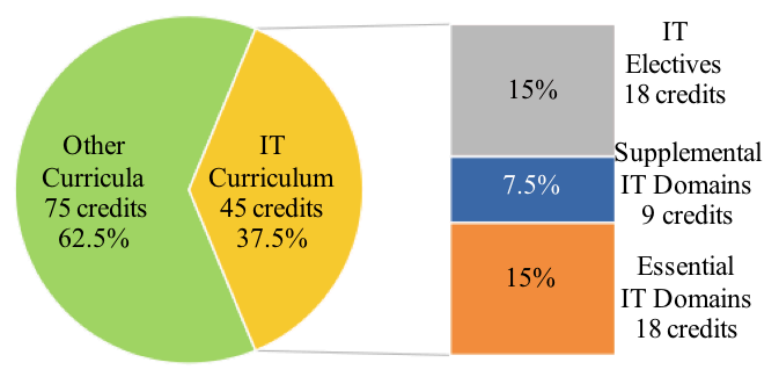

Fig. 1. Example of a curriculum for an IT program of 120 credits. 
TABLE I. IT CURRICULUM WITH RELATIVE PERCENT

\begin{tabular}{|c|c|c|}
\hline IT Domains & $\begin{array}{c}\text { Essential } \\
\text { Percent }\end{array}$ & $\begin{array}{l}\text { Suppl. } \\
\text { Percent }\end{array}$ \\
\hline \multicolumn{3}{|l|}{ Essential Only (5) } \\
\hline Information Management (IMA) & $6 \%$ & \\
\hline Integrated Systems Technology (IST) & $3 \%$ & \\
\hline Platform Technologies (PFT) & $1 \%$ & \\
\hline System Paradigms (SPA) & $6 \%$ & \\
\hline User Experience Design (UXD) & $3 \%$ & \\
\hline Subtotal: & $19 \%$ & \\
\hline \multicolumn{3}{|l|}{ Essential + Supplemental $(5+5)$} \\
\hline $\begin{array}{l}\text { Cybersecurity Principles (CSP) / } \\
\text { Cybersecurity Emerging Challenges (CEC) }\end{array}$ & $6 \%$ & $4 \%$ \\
\hline $\begin{array}{l}\text { Global Professional Practice (GPP) / } \\
\text { Social Responsibility (SRE) }\end{array}$ & $3 \%$ & $2 \%$ \\
\hline $\begin{array}{l}\text { Networking (NET) / } \\
\text { Applied Networks (ANE) }\end{array}$ & $5 \%$ & $4 \%$ \\
\hline $\begin{array}{l}\text { Software Fundamentals (SWF) / } \\
\text { Software Development \& Management (SDM) }\end{array}$ & $4 \%$ & $2 \%$ \\
\hline $\begin{array}{l}\text { Web and Mobile Systems (WMS) / } \\
\text { Mobile Applications (MAP) }\end{array}$ & $3 \%$ & $3 \%$ \\
\hline Subtotal: & $21 \%$ & \\
\hline \multicolumn{3}{|l|}{ Supplemental Only (4) } \\
\hline Cloud Computing (CCO) & & $4 \%$ \\
\hline Data Scalability and Analytics (DSA) & & $4 \%$ \\
\hline Internet of Things (IOT) & & $4 \%$ \\
\hline Virtual Systems and Services (VSS) & & $4 \%$ \\
\hline IT2017 Recommended IT Curriculum & $40.0 \%$ & $20.0 \% *$ \\
\hline
\end{tabular}

"IT2017 task group defines three levels, L1, L2, and L3 as a measurement of learning engagement for each subdomain. Ultimately, individual programs determine these levels relative to actual curricular requirements in their programs, pedagogical approaches, and assessments of student learning. Under no circumstance do these levels reflect the prominance of any subdomain since every subdomain is important. Note that the L2 level subsumes L1 and that the L3 level subsumes L2. Inspiration for the level system comes from Jerome Bruner's classic book, "The Process of Education" [17] and the notion of spiral curriculum for "continual broadening and deepening of knowledge." [1, p48]

\section{B. Distilling the IT Curricular Framework}

1) IT Curriculum: A summary of the IT curricular framework appears in two tables in the report; one table for the essential IT domains that accumulate to approximately $40 \%$ of an IT curriculum and the other for the supplemental IT domains that accumulate to approximately $20 \%$ of an IT curriculum. The tables show the IT domains, their subdomains, and the level of learning engagement for each subdomain expressed by level indicator shown in brackets.
Tags are used to differentiate the different domains and subdomains. For example.

ITE-IMA-03 Data modeling [L3]

indicates that "data modeling" should have significant learning engagement as its level is L3; it belongs to the third subdomain of the "information management" domain, which is essential for an ITdegree program. Table II shows an example for a domain from the essential IT domains table.

2) Mathematics and Science Curriculum: The IT2017 task group recommends that a powerful IT program should have at least discrete structures (mathematics) and a selection of other mathematical experiences for preparing a competent IT professional for the mid-2020s. Institutions offering programs in information technology must ensure that students entering the program have the necessary mathematical prerequisites to engage in university-level mathematics courses. Prerequisites vary by geographic region; however, they should contain precalculus, usually taught in secondary schools or in preparatory programs. Programs should look to include as much appropriate mathematics as possible to reflect the goals and the needs of their constituents, so their graduates can achieve success in the workplace or in graduate studies. In other hand, the IT2017 task group has chosen not to recommend specific science domains related to IT programs. However, it does recommend that students undertaking an IT program engage in as much science as appropriate to achieve the goals of the program and the institution.

3) Putting It All Together: Assume an IT program consists of 120 credits (semester hours) over four years.

"Then at least 1.5 years of study consists of at least 45 credits or $37.5 \%$ of the program. The mathematics curriculum should be at least 12 credits $(10 \%)$ and the science curriculum should be at least 6 credits $(5 \%)$. Note that the other curricula in the program $(47.5 \%)$ could consist of any combination of IT and non- IT subjects reflective of the mission and needs of the program." [1, p53]

Fig. 2, taken from [1, p53], illustrates the curriculum requirements for a baccalaureate IT program.

TABLE II. EXAMPLE OF AN IT DOMAIN

\begin{tabular}{|cl|}
\hline ITE-IMA Information Management [6\%] \\
ITE-IMA-01 & Perspectives and impact [L1] \\
ITE-IMA-02 & Data-information concepts [L2] \\
ITE-IMA-03 & Data modeling [L3] \\
ITE-IMA-04 & Database query languages [L3] \\
ITE-IMA-05 & Data organization architecture [L3] \\
ITE-IMA-06 & Special-purpose databases [L1] \\
ITE-IMA-07 & Managing the database environment [L2] \\
\hline
\end{tabular}




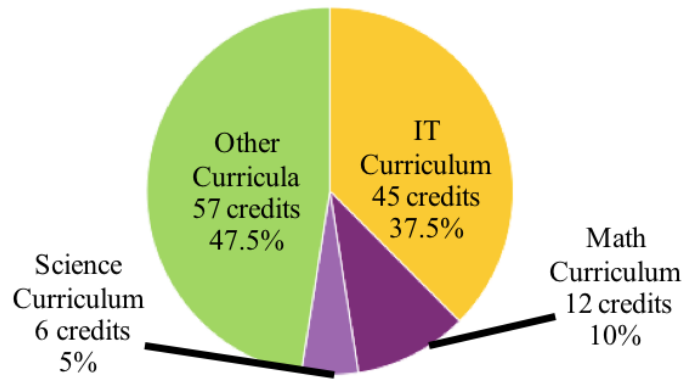

Fig. 2. Example of a curriculum for an IT program of 120 credits, with IT, mathematics, and science curricular requirements

\section{IT Domain Clusters}

The task group has selected to consolidate the descriptions of IT domains into a set of scope statements, competencies, and subdomains. This consolidation, called an IT domain cluster, uses an IT domain tag and name for identification.

\section{Contemporary Illustration of IT}

The task group has also sought to develop a contemporary illustration for information technology using essential and supplemental domains. The report states:

"The supplemental domains provide texture with enhancements and embellishments to reflect the local needs of a program's mission and constituents. That is, a modern image should depict the essential and the supplemental meanings of a curriculum carefully woven together into a tapestry of relevance and utility for the IT field." $[1, \mathrm{p} 64]$

Fig. 3, taken from [1, p65], illustrates a tapestry as a modern version of Information technology.

"For this illustration, the weft threads (vertical) of the tapestry go through the warp threads (horizontal). In this case, the ten warps represent the ten essential domains of the IT curricular framework; the nine wefts represent the nine supplemental domains of the framework. Note that one warp thread (ITE-CSP) permeates both warp and weft roles in the image, which emphasizes that cybersecurity is a contemporary 'thread' woven throughout the tapestry and hence, the field of information technology. This woven warp thread may change name over time as IT evolves. The resulting image provides a pictorial illustration showing the way IT weaves the breadth of computing." $[1, \mathrm{p} 65]$

\section{USING OF THE IT2017 FRAMEWORK IN INFORMATION TECHNOLOGY DEGREE PROGRAMS}

An IT curriculum should contain all the essential IT domains and a selection of the supplemental IT domains. This structure allows tailoring the area of specialization for a degree program. Simply selecting the most introductory competencies from every supplemental IT domain to meet the recommended supplemental $20 \%$ would likely produce a graduate with too much breadth and not enough depth to have useful skills in today's job market. The IT2017 curricular framework matches the general characteristics in several countries including China, European countries, India, Japan, Philippines, Saudi Arabia, and the United States.

It also matches the technical and professional knowledge, skills, and attitudes needed to produce a competent graduate from an IT baccalaureate program in the mid-2020s. Hence, developing of an IT baccalaureate degree program using the IT curricular framework should serve well the computing educational communities.

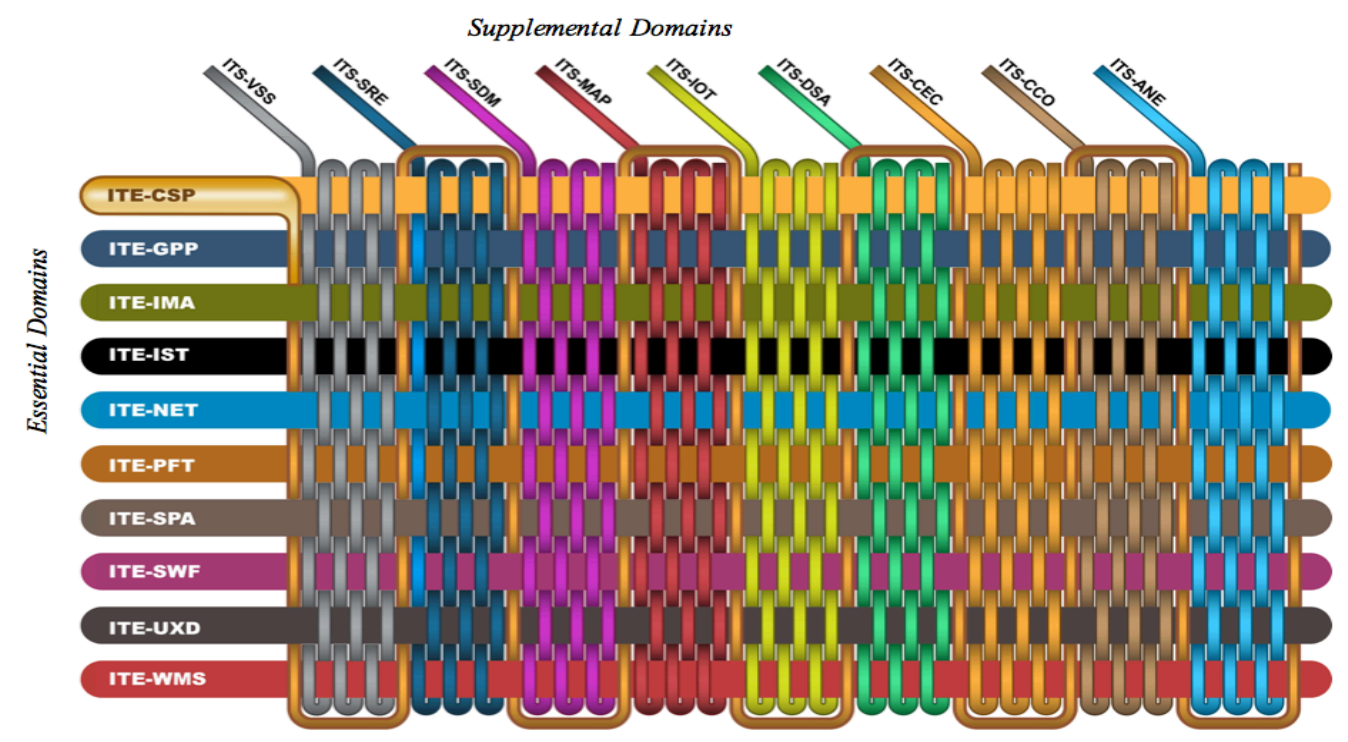

Fig. 3. Modern illustration depicting the field of IT (Courtesy of Richard Fry). 


\section{USING OF THE IT2017 FRAMEWORK IN RELATED COMPUTING PROGRAMS}

Institutions sometimes offer IT baccalaureate degree programs within a previously established discipline. This is because information technology is relatively new as a discipline. It is important to know about the curricular time available when considering ways to integrate an IT curriculum into degree programs,

\section{A. Information Technology as a Major within a Larger Degree}

A common practice is to offer an IT specialty within an existing baccalaureate degree program. In this case, the available curricular space must meet the general requirements of the degree program. Any remaining curricula may constitute IT electives.

\section{B. Information Technology Degree with a Concentration in Another Discipline}

Another common practice is to offer information technology within another discipline. In this situation, the unassigned curricular space might go to the other discipline. There may still not be enough curricular space devoted to information technology. To do this, try removing domains least relevant to the other discipline. The task group suggests that a program remove one entire domain rather than taking parts out of several domains. This is because the competencies listed within a domain interlink.

\section{Related Issues}

Information technology is a diverse field of study and its content varies by country and by region. The task group delivers samples of other information technology programs (e.g., interdisciplinary, three-year, $2+2$, etc.) that are offered within different contexts, which illustrates the breadth of information technology in different locales.

\section{CONCLUSION}

No single formula for success exists in designing an IT curriculum. Although the task group believes that the recommendations and the suggestions of the report should prove useful to a wide variety of institutions. Moreover, it is important to evaluate and modify curricular programs on a regular basis to keep up with the rapid changes in the field. Future IT curricula will depend just as much on the creativity and the academia-employer partnerships that follow in the wake of this report to build even stronger information technology programs for undergraduates throughout the world.

\section{ACKNOWLEDGMENT}

The authors thank the ACM for its sponsorship of the IT2017 project activities. They are also grateful to the IEEE Computer Society and to all the reviewers and survey respondents whose feedback and support informed the IT2017 report.

\section{REFERENCES}

[1] Task Group on Information Technology Curricula, "Information technology curricula 2017: Curriculum guidelines for baccalaureate degree programs," ACM, New York, NY, USA, 2017. http://it2017.acm.org. Accessed 2017 Dec 30.

[2] ACM Curricula Recommendations; http:// www.acm.org/education/ curricularecommendations/. Accessed 2017 Aug 25.

[3] B. M. Lunt, J. J. Ekstrom, S. Gorka, G. Hislop, R. Kamali, E. Lawson, R. LeBlanc, J. Miller, and H. Reichgelt, "Curriculum guidelines for undergraduate degree programs in information technology. technical report," ACM, New York, NY, USA., 2008.

[4] M. Sabin, P. Snow, and B. Viola, "Industry and faculty surveys call for increased collaboration to prepare information technology graduates," Journal for computing Sciences in colleges, 31, 6 (June 2016), 70-78.

[5] M. Sabin, J. Impagliazzo, H. Alrumaih, B. Byers, D. Gudoniene, M. Hamilton, V. Kotlyarov, B. Lunt, J.W. McGuffee, S. Peltsverger, C. Tang, B. Viola, and M. Zhang, "Multinational perspectives on information technology from academia and industry," In Proceedings of the 2015 ITiCSE on Working Group Reports (ITiCSE-WGR'15), 2015.

[6] M. Sabin, B. Viola, J. Impagliazzo, R. Angles, M. Curiel, P. Leger, J. Murillo, H. Nina, J.A. Pow-Sang, and I. Trejos, "Latin American perspectives to internationalize undergraduate information technology education," In Proceedings of the 2016 ITiCSE Working Group Reports (ITiCSE'16), 2016.

[7] M. Sabin, H. Alrumaih, J. Impagliazzo, B. Lunt, and M. Zhang, "Designing an information technology curriculum framework to prepare successful graduates in 2025," In Proceedings of the 2015 conference on Innovation \& technology in computer science education (ITiCSE'15). ACM, New York, NY, USA, 2015.

[8] M. Sabin, S. Peltsverger, and C. Tang, "Updating the ACM/IEEE 2008 curriculum in information technology," Abstract Only, In Proceedings of the 46th ACM Technical Symposium of Computer Science Education (SIGCSE’15), 2015.

[9] J. Impagliazzo, "Curriculum design for computer engineering and information technology," In Proceedings of the Global Engineering Education Conference (EDUCON), 2015.

[10] J. Impagliazzo, M. Sabin, H. Alrumaih, and B. Viola, "An information technology competency model and curriculum," In Global Engineering Education Conference (EDUCON), 2016 IEEE, pp. 892-895, 2016.

[11] H. Alrumaih, "ACM/IEEE-CS information technology curriculum 2017: status report," In Proceedings of the 1st National Computing Colleges Conference (NC3 2016). Saudi Arabia, 2016.

[12] M. Sabin, S. Peltsverger, C. Tang, and B. Lunt, "ACM/IEEE-CS information technology curriculum 2017: a status update," In Proceedings of the 17th Annual Conference on Information Technology Education (SIGITE'16), 2016.

[13] M. Sabin, S. Peltsverger, B. Paterson, M. Zhang, and H. Alrumaih, "IT2017 report: putting it to work. in the Proceedings of the 18th Annual Conference on Information Technology Education (SIGITE'17), 2017

[14] B. Byers, B. Paterson, and C. Hepler, "IT2017 report: panel discussion," In Proceedings of the 21 st Western Canadian Conference on Computing Education (WCCE'16), 2016.

[15] J. Impagliazzo, E. Cuadros-Vargas, G.B. Escobedo, J.J. Miranda del Solar, M. Sabin, and B. Viola, "Latin American perspectives and the IT2017 curricular guidelines," In Proceedings of the 2016 ACM Conference on Innovation and Technology in Computer Science Education (ITiCSE'16), 2016.

[16] E.K. Hawthorne, R.D. Campbell, C. Tang, C.S. Tucker, and J. Hichols, "Information technology: competency model of core learning outcomes and assessment for associate-degree curriculum. technical report,", 2014.

[17] J.S. Bruner,"The process of education," New York: Vintage, 1960. 